\title{
FAKTOR-FAKTOR KESIAPAN KERJA SISWA SETELAH PENGALAMAN KERJA INDUSTRI KELAS XI JURUSAN (TKK) TEKNIK KONSTRUKSI KAYU DAN (DPKK) DESAIN PRODUKSI KRIYA KAYU SMKN 58 JAKARTA
}

\author{
Dian Kurniawan, Rosmawita Saleh, Amos Neolaka.
}

\begin{abstract}
The Objectives of this study to find out about job readiness factors after the students practical experience working wood construction engineering industry and production design woodwork SMK 58 Jakarta. Where the research was conducted in 58 SMK Jakarta majoring in construction engineering and design wood wood craft production from May to June 2013.

This research method using survey methods. The population in this study is the class XI students majoring in Construction Engineering and Production Design Wood Craft Wood as many as 59 students and a sample of 49 students is determined by the sampling technique using simple random sampling. The instrument used was a questionnaire to gather data readiness factors working students after work experience industry practices. Reliability of the results obtained from the calculation of the value of $r$ for job readiness factors, namely the value of 0.97 for the questionnaire that has been distributed to students.

From the research that has been done on students, student work readiness factor that answers to the questionnaire students work readiness indicator has a mean value of 3.49. On indicators of industry experience work practices questionnaire answers students have an average value of 3.43 .

It can be concluded that the students' work readiness indicator most dominant and has the highest average value is 3.49. This suggests that high job readiness of every student after the experience of industrial work practices. Need for improvement in preparing students for industrial work practices in order to maximize the students to follow the practice of industry, labor and the role of government in the distribution of work graduate students SMK 58 Jakarta in particular and SMK in general
\end{abstract}

Keywords: learning achievement, student's motivation

\begin{tabular}{|l|c|r|}
\hline Tri Puspita Sari & Dra. Rosmawita Saleh, M. Pd \\
Alumni Jurusan Teknik Sipil & Jurusan Teknik Sipil \\
Fakultas Teknik & Fakultas Teknik & Prof. Dr. Amos Neolaka \\
Universitas Negeri Jakarta, 13220 & Jurusan Teknik Sipil \\
& Fakultas Teknik \\
& & $\begin{array}{r}\text { Universitas Negeri Jakarta, 13220 } \\
\text { email:amos_neolaka@yahoo.com }\end{array}$ \\
\hline
\end{tabular}




\section{PENDAHULUAN}

Sekolah menengah kejuruan (SMK) adalah lembaga formal yang bertujuan untuk menyiapkan peserta didik menjadi manusia yang produktif, yang dapat bekerja sesuai dengan bidangnya setelah melalui pendidikan, pelatihan dan juga Praktik Kerja Industri. Depdiknas (2004:3) menyebutkan bahwa Pendidikan Menengah Kejuruan di jalankan atas dasar prinsip investasi sumber daya manusia (human capital investmen). Semakin tinggi kualitas pendidikan dan pelatihan yang diperoleh seorang akan semakin produktif orang tersebut. Akibatnya selain meningkatkan produktifitas nasional juga meningkatkan daya saing tenaga kerja di pasar global. Sekolah Menengah Kejuruan harus mengadopsi nilai-nilai yang diterapkan dalam melaksanakan pekerjaan, yaitu disiplin, taat azas, efektif dan efisien. Tenaga kerja yang dihasilkan diharapkan memiliki pengetahuan, keterampilan, dan sikap kerja yang sesuai dengan kebutuhan industri.

Tetapi pada kenyataannya masih banyak siswa lulusan SMK yang menjadi pengangguran. Berdasarkan data terbaru dari Badan Pusat Statistik (BPS) data pengangguran periode Agustus 2012 mencapai 7,2 juta orang lulusan SMA dan SMK paling banyak menyumbangkan angka pengangguran. Angka pengangguran tertinggi berdasarkan level kelulusan pendidikan yang pertama adalah Sekolah Menengah Kejuruan (SMK) 9.87\%, kerja pada Siswa Setelah Pengalaman Praktik Kerja Industri Kelas XI Jurusan TKK (Teknik
Sekolah Menengah Akhir (SMA) 9.6\%, Sekolah Menengah Pertama 7.76\%, Diploma I/I//II $6.21 \%$, Universitas $5.91 \%$, dan SD kebawah $3.64 \%$.

Praktik Kerja Industri merupakan suatu ajang dimana siswa dapat mengaplikasikan ilmu yang didapat di sekolah ke dunia kerja begitu sebaliknya bahwa pengalaman-pengalaman baru tentang hal-hal yang berhubungan dengan dunia kerja diaplikasikan melalui Praktek Kerja Industri dan data tersebut dapat dijadikan sebuah gambaran tentang kesiapan kerja siswa smk untuk lebih mempersiapkan diri. Seperti halnya yang dilakukan oleh SMKN 58 Jakarta yang mengaplikasikan Praktik Kerja Industri. Praktik Kerja Industri dapat menimbulkan rasa kesiapan kerja saat mereka sudah lulus SMK. Begitu banyak faktor yang dapat mempengaruhi kesiapan kerja bagi siswa SMK N 58 Jakarta. Seperti kita ketahui bahwa anak SMK pada umumnya dipersiapkan untuk langsung terjun langsung ke dunia kerja.

Berdasarkan pemaparan diatas, maka peneliti tertarik untuk melakukan penelitian tentang : "Analisis Faktor Kesiapan Kerja Siswa Setelah Pengalaman Praktik Kerja Industri Peserta Didik Kelas XI Jurusan TKK (Teknik Konstruksi Kayu) dan DPKK (Desain Produksi Kriya Kayu) SMKN 58 Jakarta".

Tujuan penelitian ini adalah untuk mengetahui faktor-faktor yang menjadi kesiapan 
Konstruksi Kayu) dan DPKK (Desain Produksi Kriya Kayu) SMKN 58 Jakarta. Penelitian ini dilakukan di Penelitian ini dilakukan di SMKN 58 Jakarta Jalan SMIK Bambu Apus Pada semester genap tahun pelajaran 2012/2013 terhitung dari bulan Mei s/d Juni 2013.

Jenis penelitian yang digunakan dalam penelitian ini adalah penelitian deskriptif dengan metode survei. Hal tersebut untuk mengetahui adanya faktor yang menjadi kesiapan kerja setelah mengikuti Prakerin kelas XII Jurusan TKK (Teknik Konstruksi Kayu) dan DPKK (Desain Produksi Kriya Kayu) SMKN 58 Jakarta
Yang merupakan populasi dari penelitian ini adalah seluruh siswa kelas XI SMKN 58 Jakarta Jurusan TKK (Teknik Konstruksi Kayu) dan DPKK (Desain Produksi Kriya Kayu) yaitu terdiri dari dua kelas yang nantinya dua kelas tersebut menjadi fokus untuk pengambilan sampel. Sampel yang digunakan dalam penelitian ini menggunkan teknik random sampling dengan galat kesalahan $5 \%$ untuk menentukan jumlah sample responden mahasiswa. Ditentukan sample mahasiswa berjumlah 49 siswa. Berikut data yang dapat disajikan:

Tabel 1. Jumlah Populasi dan Sampel penelitian

\begin{tabular}{|c|c|c|}
\hline Kelas XII & Populasi & $\begin{array}{c}\text { Sampel } \\
\text { Penelitian }\end{array}$ \\
\hline TKK & 30 & 25 \\
\hline DPKK & 29 & 24 \\
\hline JUMLAH & 59 Siswa & 49 Siswa \\
\hline
\end{tabular}

Pada penelitian ini lebih cocok dengan menggunakan teknik pengambilan simple random sampling atau sampel acak dikarenakan subjek-subjek yang berada di dalam populasi dianggap sama, selain itu dengan pertimbangan keterbatasan waktu, tenaga, dan dana. (Suharsimi 2010:177). Teknik ini dilakukan karena beberapa pertimbangan, yaitu adanya keterbatasan waktu, tenaga, dan dana sehingga tidak dapat mengambil sampel yang besar dan jauh. (Suharsimi 2010:183).
Data yang dibutuhkan dalam penelitian ini diperoleh melalui sebuah instrumen. Instrumen penelitian yang digunakan dalam penelitian ini adalah berbentuk instrument non-tes. Angket ini disusun berdasarkan kisi-kisi yang telah dibuat. Angket ini berisi pertanyaan untuk menjaring tentang faktor-faktor kesiapan kerja siswa.

\section{METODE PENELITIAN}

Adapun prosedur atau langkah-langkah yang ditempuh dalam pembuatan kuesioner adalah sebagai berikut : 
a. Menentukan indikator-indikator yang menjadi dasar dalam penyusunan butirbutir pernyataan yang dan membuat kisikisi instrumen penelitian. menyusun rancangan kuesioner kemudian dikonsultasikan dengan dosen pembimbing untuk diberikan saran, pendapat, dan perbaikan. Kemudian dibuat kuesioner yang sebenarnya. Angket kuesioner tersebut berisi data responden dan pertanyaan-pertanyaan. Kedua alat pengumpulan data tersebut digunakan dalam penelitian ini, pengisiannya dapat dilakukan dengan cara mengisi dan membubuhkan tanda check list $(\sqrt{ })$ pada kolom yang tersedia. Dalam setiap butir pertanyaan responden dapat memilih salah satu dari 5 alternatif jawaban yang disediakan. Dari kelima alternatif jawaban tersebut untuk pernyataan positif masingmasing diberi skor 5 untuk selalu, 4 untuk sering, 3 untuk ragu-ragu, 2 untuk kadangkadang, dan 1 untuk tidak pernah, dan untuk pernyataan negatif diberi skor 5 untuk tidak pernah, 4 untuk kadangkadang, 3 untuk ragu-ragu, 2 untuk sering, dan 1 untuk selalu.

b. Melakukan uji coba (pre-test) kepada 10 responden untuk menguji validitas dan reliabilitas dari instrumen penelitian. Setelah dilakukan analisis hasil uji coba diperoleh tingkat validitas, diperoleh. 9 butir pernyataan tidak valid dari 41 butir pernyataan yang valid. Dari pretest yang telah dilakukan, kedua angket meiliki nilai reliabilitas yang sama yaitu diperoleh $\left(r_{x x}\right)=$ 0,97 . Dengan melihat nilai $r_{x x}=0,97$, maka dapat dikatakan bahwa nilai tersebut memiliki nilai reliabilitas tinggi, karena 0,97 terletak antara $0,80-1$.Setelah instrumen tersebut dinyatakan valid dan reliabel, selanjutnya dilakukan penelitian yang sebenarnya terhadap sampel yang dijadikan responden.

\section{HASIL DAN PEMBAHASAN}

Berdasarkan perhitungan data tentang Analisis Faktor Kesiapan Kerja Siswa Setelah Pengalaman Praktik Kerja Industri Jurusan Teknik Konstruksi Kayu (TKK) dan Desain Produksi Kriya Kayu (DPKK) SMKN 58 Jakarta diketahui bahwa:

a. Nilai rerata untuk indikator kesiapan kerja pada hasil angket siswa mempunyai nilai sebesar 3,49.

b. Nilai rerata untuk indikator pengalaman praktik kerja industri pada hasil angket mempunyai nilai sebesar 3,4 . 
Tabel 2. Hasil Penelitian

\begin{tabular}{|c|c|c|c|}
\hline Indikator & Sub Indikator & $\begin{array}{l}\text { Nilai rerata } \\
\text { Sub-Indikator }\end{array}$ & $\begin{array}{l}\text { Jumlah rerata masing- } \\
\text { masing Indikator } \\
\text { (angket Siswa) }\end{array}$ \\
\hline \multirow{8}{*}{ Kesiapan Kerja } & $\begin{array}{l}\text { Memiliki pertimbangan yang } \\
\text { logis dan objektif }\end{array}$ & 3.76 & \multirow{8}{*}{3,49} \\
\hline & Sikap kritis & 3.76 & \\
\hline & Pengendalian emosional & 3.05 & \\
\hline & $\begin{array}{c}\text { Kemampuan beradaptasi } \\
\text { dengan lingkungan }\end{array}$ & 3.37 & \\
\hline & Bertanggung jawab & 3.88 & \\
\hline & Mempunyai ambisi untuk maju & 3.35 & \\
\hline & $\begin{array}{l}\text { Mengikuti perkembangan } \\
\text { bidang keahlian }\end{array}$ & 3.36 & \\
\hline & $\begin{array}{c}\text { Kemampuan bekerjasama } \\
\text { dengan orang lain }\end{array}$ & 3.44 & \\
\hline \multirow{4}{*}{$\begin{array}{l}\text { Pengalaman } \\
\text { Praktik Kerja } \\
\text { Industri }\end{array}$} & Pengetahuan kerja & 3.19 & \multirow{4}{*}{3,43} \\
\hline & Sikap kerja & 3.40 & \\
\hline & Keterampilan kerja & 3.32 & \\
\hline & Kreatifitas kerjasiswa & 3.81 & \\
\hline
\end{tabular}

Dari tabel tersebut Kesiapan Kerja Siswa terhadap indikator kesiapan kerja mempunyai nilai rerata sebesar 3,49 . Berdasarkan faktor kesiapan kerja yang paling dominan sub indikator dapat dijabarkan dari nilai tetinggi sampai nilai terendah sebagai berikut :

1. Memiliki sikap bertanggung jawab

2. Memiliki pertimbangan logis dan objektif

3. Memiliki sikap kritis

4. Memiliki kemampuan bekerjasama dengan orang lain

5. Mampu beradaptasi dengan lingkungan

6. Mengikuti perkembangan bidang keahlian
7. Mempunyai ambisi untuk maju

8. Mampu mengendalikan emosional.

Dari hasil penelitian yang telah dilakukan, dapat disimpulkan bahwa siswa sudah siap untuk terjun ke dunia kerja setelah pengalamannya dalam praktik kerja industri. Dengan pengalaman yang di dapat selama praktik kerja industri menjadikan siswa memiliki rasa bertanggung jawab yang tinggi yang sangat dibutuhkan dalam bekerja. Tanggung jawab yang timbul pada siswa setelah ia memiliki kematangan fisik dan mental yang disertai dengan kesadaran tiap siswa tersebut. Dengan 
kematangan yang dimiliki siswa berpengaruh terhadap pertimbangan yang tidak hanya di lihat dari satu sudut pandang saja tetapi siswa akan menghubungkannya dengan hal-hal yang masuk akal dan mempertimbangkannya dengan melihat pengalaman orang lain.

Siswa dengan sikap kritis yang dimilikinya dapat mengkoreksi kesalahan atau ketidaksesuaian tidak hanya untuk diri sendiri tetapi juga lingkungan di mana ia berada yang selanjutnya dapat memutuskan tindakan apa yang dilakukan setelah mengkoreksinya. Sikap kritis yang dimiliki juga harus diimbangin dengan sikap untuk dapat bekerja sama dengan orang lain. Dunia kerja sangat di tuntut untuk dapat bekerja sama dengan orang lain karena dalam dunia kerja nanti siswa diharapkan dapat berinteraksi baik dengan orang lain. Selain berinteraksi dengan orang lain, siswa juga memiliki kemampuan beradaptasi dengan lingkungan kerja karena lingkungan kerja merupakan modal untuk dapat berinteraksi dalam lingkungan tersebut. Berinteraksi dalam lingkungan kerja dapat diawali sejak siswa mengikuti praktik kerja industri sebelum siswa terjun ke dunia kerja. Pada saat praktik kerja industri siswa dapat dunia kerja yang sebenarnya dan dapat berlatih untuk menyesuaikan diri dengan lingkungan kerja.

Seiring dengan berkembangnya zaman dan teknologi terutama untuk bidang keahlian, siswa diharapkan dapat meningkatkan ambisi untuk maju dengan mengikuti perkembangan bidang keahlianya. Masih kurang dan terbatasnya fasilitas yang menujang di lingkungan sekolah dan juga kurangnya minat siswa untuk mengikuti kursus, seminar dan juga pelatihan untuk menambah keterampilan siswa. Pada pengendalian emosi siswa masih kurang dalam mengendalikan emosinya. Pengedalian emosi yang sangat dibutuhkan agar dalam siswa mampu mengatasi masalah dengan tenang dan menyelesaikan suatu pekerjaan dapat diselesaikan dengan baik dan benar.

\section{KESIMPULAN}

Berdasarkan deskripsi, analisis, dan interpretasi data yang telah diuraikan pada babbab sebelumnya, dapat di tarik kesimpulan sebagai berikut :

a. Pada sub indikator kesiapan kerja nilai tertinggi terdapat pada memiliki sikap bertanggung jawab dengan nilai sebesar 3,88. Nilai tersebut menunjukkan siswa memiliki tanggung jawab yang baik.. Nilai terendah terdapat pada sub indikator pengendalian emosional dengan nilai sebesar 3,05 . Nilai tersebut menunjukkan kurangnya pengendalian emosional yang dimiliki siswa.

b. Pada sub indikator pengalaman praktik kerja industri nilai tertinggi terdapat pada kreatifitas kerja dengan nilai sebesar 3,81. Selama praktik kerja industri siswa menjadi lebih kreatif dalam melakukan pekerjaan. Nilai terendah terdapat pada sub indikator pengetahuan kerja dengan nilai sebesar 3,19. Nilai tersebut menunjukkan masih kurangnya keterampilan yang dimiliki sebagian siswa dalam bekerja. 
Implikasi

Berdasarkan hasil penelitian, tindak lanjut yang dapat diberikan adalah sebagai berikut :

a) Siswa harus lebih aktif dalam mengikuti perkembangan ilmu pengetahuan dan teknologi serta mempersiapkan diri sebelum mengikuti praktik kerja industri agar bekal yang di dapat di sekolah dapat dengan baik dimanfaatkan di dunia kerja.

b) Pengalaman yang di dapat saat praktik kerja industri harus dapat dimanfaatkan dengan sebaik mungkin agar siswa semakin siap untuk terjun di dunia kerja.

c) Perlu diberikan pembekalan dan pelatihan yang cukup sebelum siswa melaksanakan praktik kerja industri.

d) Dilakukan pembinaan sikap yang dilakukan oleh wali kelas maupun guru pembing disekolah agar siswa memiliki gambaran tentang sikap yang baik dalam dunia kerja.

e) Guru pembimbing selama praktik kerja industri untuk mempersiapkan dan menjadikan siswa lebih berkompetensi untuk disiapkan kedunia kerja khususnya dalam pengendalian emosianal siswa, sehingga nantinya siswa dapat bersaing dan berkompetisi dalam dunia kerja.

\section{Saran}

Berdasarkan kesimpulan dan implikasi diatas dapat dikemukakan saran-saran sebagai berikut :

a. Sekolah hendaknya lebih memfasilitasi siswa dalam perkembangan ilmu pengetahuan dan teknologi sehingga menjadikan siswa lebih siap dan memiliki ambisi untuk maju serta mengikuti perkembangan bidang keahlian.

b. Mempersiapkan strategi pembelajaran dalam meningkatkan kualitas pembelajaran agar siswa lebih mandiri, bermoral dan siap untuk terjun di dunia kerja

c. Siswa hendaknya memanfaatkan waktu selama praktik kerja industri dengan baik karena pengalaman yang didapat saat praktik kerja industri sangat bermanfaat terhadap kesiapan bekerja

Penelitian ini masih terbatas pada deskriptif faktor kesiapan kerja siswa setelah pengalaman praktik kerja industri, oleh karena itu perlu adanya penelitian lebih lanjut lagi pada faktor kesiapan kerja internal maupun eksternal.

\section{DAFTAR PUSTAKA}

Amirin, Tatang M. 2011. Populasi dan sampel penelitian 4: Ukuran sampel rumus Slovin. Tatangmanguny.wordpress.com

Arikunto, Suharsimi.2010. Prosedur Penelitian Pendidikan. Jakarta : PT Rineka Cipta.Buku Pedoman Skripsi/Komprehensif/Karya Inovatif (S1). Jakarta: FT UNJ Press.2009.

Chalpin, J. P.2006. Kamus Lengkap Psikologi (TerjemahanKartiniKartono. Jakarta: PT Raja Grafindo Persada.

Danielson.2008. Pendidikan Kejuruan. Jakarta: Gramedia.

Depdiknas.2005. Kamus Besar Bahasa Indonesia. Jakarta:Balai Pustaka.

Depdiknas.2006. UU Sistem Pendidikan Nasional pasal 15. Jakarta: Depdiknas. 
Djaali dan Pudji Muljono.2008. Pengukuran dalam Bidang Pendidikan. Jakarta: Grasindo.

Finch and Curtis R. Crunkilton, John R.1999. Curriculum Development in Vocational and Technical Education Planing, Content, and Implementation (5thed). Bostom: Allyn and Bacom.

Fitriyanto, Agus.2006. Ketidakpastian Memasuki Dunia Kerja Karena Pendidikan. Jakarta: Dineka Cipta.

G,Rizki.2012.DataPengangguran.(Online).Tersed ia.http://m.liputan6.com/read/450197/72jutaorangindonesiastatusnyapengangguran[diakses 5 November 2012].

Hamalik, Oemar.2008. Proses Belajar Mengajar. Jakarta: Bumi Aksara.

Indaryani, Nevi.2007. Hubungan Praktik Industri dan Motivasi Berprestasi dengan Kesiapan Kerja Kelas XII Program Keahlian Akuntansi SMKN 1 Pedan Tahun Ajaran 2006/2007.Skripsi.Yogyakarta:UNY

Kartono, Kartini.1991. Menyiapkan dan Memandu Karier. Jakarta: Rajawali Pers.

Ketut, Dewa.1993. Bimbingan Karir di Sekolahsekolah.Jakarta:Ghalia Indonesia.
Made, Wena.1996. Pendidikan Sistem Ganda. Bandung: Tarsito.

Manribu, M.T.1998. Pengantar Bimbingan dan Konseling Karir.Jakarta: Depdikbud.

Nolker, Helmut and Eberhard Schoenfeldt.1988. Pendidikan Kejuruan: Pengajaran, Kurikulum, Perencanaan, Diterjemahkan oleh : Agus Setiadi. Jakarta : Gramedia.

Renita,B.2006. Bimbingan dan Konseling SMA I untuk Kelas X. Jakarta: Penerbit Erlangga

Sofyan, Herminanto.1986. Kesiapan Kerja STM Se-Jawa untuk memasuki Lapangan Kerja. Yogyakarta: Jurnal Pendidikan Lembaga Penelitian IKIP Yogyakarta.

Slameto. 2010. Belajar dan Faktor-faktor yang Mempengaruhi. Jakarta: Rineka Cipta.

Sugiyono.2007. Metode Penelitian Pendidikan. Bandung : Alfabeta.

Wijaya, Aziiz Aji.2012. Pengaruh Prestasi Mata Pelajaran K3 dan Pengalaman Praktik Industri Terhadap Kesiapan Kerja pada Siswa Kelas XII SMK Muda Patria Kalasan. Skripsi.Yogyakarta:UNY

Wijayanti, Dwiyana.2009. Pengaruh Praktik Kerja Industri, Motivasi Memasuki Dunia Kerja Siswa Kelas XII Program Keahlian $\begin{array}{llll}\text { Akuntansi SMK N } & \text { N }\end{array}$ Magelang.Skripsi.Yogyakarta:UNY.. 